\title{
Determinants of Technical University Students' Choice of Banks: Empirical Evidence from Takoradi Technical University, Ghana
}

\author{
Emmanuel Mensah Baah1, Emefa Akua Amponsah², Robertson Asare 0too1 \\ ${ }^{1}$ Department of Mathematics, Statistics and Actuarial Science, Faculty of Applied Sciences, Takoradi Technical University, \\ Sekondi-Takoradi, Ghana \\ ${ }^{2}$ Department of Textile Design and Technology, Faculty of Applied Arts and Technology, Takoradi Technical University, \\ Sekondi-Takoradi, Ghana \\ Email: emmanuel.baah@ttu.ed.gh
}

How to cite this paper: Baah, E.M., Amponsah, E.A. and Otoo, R.A. (2021) Determinants of Technical University Students' Choice of Banks: Empirical Evidence from Takoradi Technical University, Ghana. Open Journal of Statistics, 11, 351-368. https://doi.org/10.4236/ojs.2021.113021

Received: April 4, 2021

Accepted: May 28, 2021

Published: May 31, 2021

Copyright (c) 2021 by author(s) and Scientific Research Publishing Inc. This work is licensed under the Creative Commons Attribution-NonCommercial International License (CC BY-NC 4.0). http://creativecommons.org/licenses/by-nc/4.0/

\begin{abstract}
Background: The current competitive banking environment in Ghana demands that banks identify the factors key to their survival and work on these factors to ensure they remain in business. This involves the banks knowing what influences customers to choose to do business with one bank over the other. Objective: The study aimed at determining the factors the influence Technical University student's selection of banks. Methods: Data from a cross-sectional survey of 545 student respondents of Takoradi Technical University was analysed using the statistical technique of factor analysis. Results: Four factors were adduced to be influencing bank selection amongst Takoradi Technical University students: namely, Robust E-banking, Customer Experience, Access to ATMs and Third Party Influence. Conclusion: While some of the factors are universal in nature others present with subtle nuances dependent on the milieu in which a bank finds itself, making it imperative that banks study the market in which they are operating and implement strategies deemed most suitable for attracting and retaining customers.
\end{abstract}

\section{Keywords}

Bank Choice, Customers, Technical Universities, Students, Factor Analysis

\section{Introduction}

The Bank of Ghana (the central bank of Ghana) recently embarked on a major cleanup of the financial sector in Ghana, with particular attention on banks. The cleanup led to the closure of some banks and others merging to be able to meet 
the minimum capital requirement. This cleanup saw customers losing faith and becoming skeptical in dealing with banks in Ghana. The Ghanaian financial sector began to see a major transformation in the late 2000s with an attendant increase in the number of financial institutions operating in the country, including banks [1]. In particular, the banking sector became competitive, requiring banks to be innovative, effective, and customer-oriented in their bid to be profitable [2] [3], and with the right environment adapt and grow. The competition in the banking sector and the skepticism that attended the cleanup pose some challenges for all banks, irrespective of size Mokhlis [4] or orientation since it is now relatively easy for customers to switch from one bank to another, should they not be content with the range of products and quality of service their banks are offering [5]. Chigamba and Fatoki [6] indicated that banks are focusing on developing custom-made products and services that enhance their profitability and enable them to exist and survive in the competitive market. Banks rely on customers to be able to survive [2]. Kumar, Batista, and Maull [7] attest that the ability of an organization to exist, operate, thrive and be profitable depends on its customer base. They indicated that an organization needs to work at formulating and implementing strategies that will build, grow, and maintain its customer base. Banks are organizations that focus on different market segments to enable them to broaden their customer base. Dogbe, Bamfo and Sarsah [2] indicate that the students market is an attractive segment for some banks and they tend to establish branches in localities where students are located. These banks provide specific products tailored to the needs of this young and vibrant segment of their clientele [8]. Providing products and services for this segment-university students-creates room for developing a loyal customer base who grow with the bank and are likely to remain with it after the completion of their education. This market segment will gain employment in several fields after completing their education and will rely on these banks for their financial needs. Incidentally, studies in Ghana on banking choice among tertiary University students focused on traditional universities [9].

The Technical Universities sector of Ghana is made up of at least ten former government run Polytechnics who were recently converted into Technical Universities. As the name indicates, Takoradi Technical University is one of the Technical Universities in Ghana. It is located in the western region of Ghana. The University had a student population of twelve thousand, two hundred and ninety-four (12,294: personal communication, March 25, 2020) students in programmes at the certificate, diploma, bachelors and the masters levels in technical and business-oriented programmes as at the time of the study. This diverse range of students constitutes a broad market for banking institutions that believe in providing services that would enable them to acquire a loyal customer base with the objective of having a greater share [10] of the student market, which holds the potential for above-average profitability in the future. Duncan, Boisjoly and Smeeding [11] reiterate this by indicating that university graduates tend 
to have a significantly higher than average chance of improving their wellbeing with time. Adekiya and Gawuna [12] argue that graduates of college have a high probability of acquiring professional jobs that provide higher incomes as compared to people with lower educational achievements. This explains why banks need to identify factors that influence student choice of banks and work on improving their performance relative to these factors. Owing to the level of concentration of banks in the country, it is in the interest of banks to provide products and services for all the categories of students within the educational sector in order to broaden the base of their clientele to enable them to thrive, survive the competition and sustain their growth.

Studies on banking choice in Ghana focused on students from the traditional universities [3] [9] [13] [14] and not on the Technical Universities. This study seeks to identify the factors that influence Technical University students' choice of banks using Takoradi Technical University as a case study. The study explores some demographic, social and technological factors that influence student's choice of a bank. Banks need to explore all the factors that influence banking choice by all the segments within the tertiary space to enable them to provide customized services for the prospective clients. Failure to capture these clients and provide customized services to them within the competitive tertiary space may lead to banks losing out on a group of prospective customers who may provide the bank with loyal customer base for their sustenance in the future. As such knowing the factors that determine banking choice among students from the Technical Universities sector could help to identify and implement marketing strategies that may suit their needs and thereby attract and retain them.

As hinted above, the study reported herein was carried out to find what informs Technical University students' bank choice. More precisely, the objective was to find what factors influence the choice of banks by Technical University students, using Takoradi Technical University as a case study.

\section{Background Information}

According to Mokhlis, Mat and Salleh [8] and Gakure [10] several factors such as reputation, service quality and availability of information influence banking choice among tertiary students. Dogbe, Bamfo and Sarsah [2], Amewu and Mensah [3], Azumah, Rahman and Adzawla [9], Abbam, Dadson and Sey [14] identified proximity to bank, availability of ATM, convenience, among others as reasons why people prefer one bank over the other. Varied factors, in diverse cultures and contexts, were found to influence students' bank choice by these studies.

Studies in the United States by Khazeh and Decker [15] and in Nigeria by Maiyaki [16] identified reputation of banks as a factor that influences banking choice. Amewu and Mensah [3], in addition to reputation, identified systems efficiency as a factor. They explained systems efficiency as having access to a regular working banking system. They [3] further described system's efficiency to include the provision of access to a reliable and uninterrupted range of banking products 
and services at different locations. Azumah, Rahman and Adzawla [9] and Abbam, Dadson and Sey [14] indicated among other factors that the quality of service, short turnaround time and availability of technology all help to influence bank choice. Banks that have a professional and friendly staff with lower bank charges as well as good reputation are the banks most likely to be selected by customers.

Khazeh and Decker [15] in the United States, Akin and Kaya [17] in Turkey and Abbam, Dadson and Sey [14] in Ghana observed that the kind of experience customers have with a particular bank could determine if they will stay with that bank or not. Customer experience is influenced by the convenience of service [18]. Blankson, Cheng and Spears [13] indicated that in addition to convenience, the location of the bank, the regularity and reliability of its ATMs and the ease of service; all influence banking choice. According to Mariam [19], in a study in Kenya, availability of information on customer's account and banks promotion strategy influence bank selection. Other factors include quality of service, professionalism of the staff [20], friendliness of personnel [21], fast and efficient service, and shorter waiting time [3] [22].

Availability and location of the ATMs were found to be important by Almossawi [23] in Bahrain. For Karamustafa and Yıldırım [24] availability of ATMs with multiple reliable service offerings and short turnaround time are highly important factors that have impact on bank preferences among students. Gakure [10] corroborates availability of ATMs as a factor that influence student bank choice through a study involving executive MBA students. The study further identified bank charges, tariffs, and the location of a bank as important factors in bank choice. The above-mentioned studies appear to suggest that students place premium on the availability and location of ATMs at vantage points, since they help to reduce the waiting time at the banks while making transactions faster.

Several studies found a number of factors, both social and demographic in nature that determine bank choice among students. Almossawi [23] identified peer group influence and reputation in Bahrain. Amewu and Mensah [3] pointed to proximity of bank to home, workplace and business area as factors that influence students choosing one bank over the other. Recommendations by friends and families is also ranked important in determining bank choice by customers. Studies by Almossawi [23], Anderson, Cox and Fulcher [25], Kennington, Hill and Rakowska [26], Tan and Chua [27], Yavas [28] and Denton and Chan [29] identified recommendations from family and friends as an important factor that influence customers' bank selection and bank choice. These studies explained that good experiences with banks encourage customers to refer others to them (banks).

According to Almossawi [23] recommendations from third parties including family and friends influence people's banking choice. Customers base their choice of banks, to some degree, on the experiences of their friends and associates. His study however reiterates that young people usually prefer to make independent choices than rely on recommendations by friends and family. Ger- 
rard and Cunningham [30] had a divergent opinion when they showed that recommendations by family and friends played little role in the banking choice of their respondents. Azumah, Rahman and Adzawla [9] in addition to recommendations by the family found that convenience, no banking charges and competence ranked higher in influencing banking choice by respondents.

Generally, customers consider their individual satisfaction in deciding on which bank to opt for. Improvement in technology and the competiveness of the banking sector have led to innovation [9], making banking relatively easy and convenient. Customers of banks have also grown in sophistication, preferring quality and improved services when choosing which bank to do business with. Tertiary student customers have the potential of earning higher incomes and accumulating wealth over time. They are, therefore, potentially good source for building a solid customer base [11] [12]. There is the need for banks to provide the right products and services in a professional yet friendly environment to satisfy the needs of the ever-changing customer profile, and to entice and retain the custom of students and make them want to continue doing business with them as they transition into the world of work.

\section{Review of Methods}

This paper concerns the results of an analysis of data collected in a cross-sectional survey of students of Takoradi Technical University, Ghana, using the statistical method of factor analysis, in $\mathrm{R}$-a statistical computing environment [31].

\subsection{Collection of Data}

Students of the University were sent home following the suspension of on-campus academic activities announced by the government of Ghana on March 15, 2020, owing to the COVID-19 pandemic. As a result of the need for physical distancing to prevent the spread of the COVID-19 disease, students were allowed to come for the end-of-second-semester examinations in stages, with final year students coming first, followed by second year students and other groups other than first year students; and then, finally, first year students. The return to campus for the end-of-second-semester examinations took place over the period of July to November 2020. It was during this period that the data was collected. The whole student body was therefore not available at any one point in time during this period. As many students as possible were interviewed when the various groups identified above were on campus, with a questionnaire made up of 25 items, each of which measures the responses on a 5-point differential scale ranging from 1-“strongly disagree" to 5- "strongly agree". A total of $641 \mathrm{stu}$ dents were interviewed while adhering to strict COVID-19 preventive protocols. However 96 of the respondents did not provide answers for all the items so the data relating to these 96 respondents were not included in the analysis, leaving an effective sample size of 545. According to Hair, Black, Babin, Anderson and Tatham [32], the sample size should be at least five times the number of va- 
riables under consideration in a study, for the method used in the analysis of the data. Thus the sample size of 545 was more than adequate for the method of analysis employed in this study.

While it would have been preferable to collect data from all the Technical Universities in the country to ensure external validity of the study results, the contagious nature of the COVID-19 disease dictated that the study was restricted to Takoradi Technical University to forestall the possibility of unwittingly spreading the disease through the study.

\subsection{Statistical Methods}

As hinted above, factor analysis was employed in the analysis of the data. The use of the method of factor analysis in trying to understand the factors that inform bank choice amongst university students is not common in the Ghanaian context. In particular it appears to be the first time the approach has been applied in the Technical Universities setting to study what motivates students' bank choice. A review of some of the key issues involved with factor analysis is presented below:

\subsubsection{Factor Analysis}

The interdependence among variables and the latent dimensions (factors) that account for the interdependence can be studied using factor analysis. It provides a means through which latent factors that are common to (correlate with) groups of variables are identified, enabling one to replace each group of variables with the corresponding latent factor. A large set of variables could be replaced by a new smaller set of variables (factors) that essentially retain the information in the original set of variable using this procedure. The unobserved factors permits the interpretation of any observed phenomenon better than do the original set of variables, hence their importance [32] [33] [34] [35].

\subsubsection{Data Model}

The data model is cast in matrix notation as follows:

$$
(X-\mu)_{p \times 1}=L_{p \times m} F_{m \times 1}+\varepsilon_{p \times 1}, \quad m \ll p
$$

where $L_{p \times m}$ is a $p \times m$ matrix composed of the coefficients

$$
\begin{gathered}
l_{i j}, i=1,2, \cdots, p ; j=1,2, \cdots, m . \\
X^{\prime}=\left(X_{1}, X_{2}, \cdots, X_{P}\right) \text { is the vector of observable (indicator) }
\end{gathered}
$$

variables,

$\mu=E[X]=\left(\mu_{1}, \mu_{2}, \cdots, \mu_{p}\right)^{\prime}$ is the mean of the $X$,

$F^{\prime}=\left(F_{1}, F_{2}, \cdots, F_{m}\right)$ is the vector of latent factors,

$\varepsilon^{\prime}=\left(\varepsilon_{1}, \varepsilon_{2}, \cdots, \varepsilon_{p}\right)$ is the vector of possible error terms

associated with each $X_{i}, i=1,2, \cdots, p$ respectively,

and the mean corrected vector

$(X-\mu)_{p \times 1}$ is the response variable [33]. 
The following conditions must hold if $F^{\prime}=\left(F_{1}, F_{2}, \cdots, F_{m}\right)$ are to be uncorrelated (orthogonal):

$$
\begin{gathered}
E[F]=O_{(m \times 1)}, E[\varepsilon]=O_{(p \times 1)}, \operatorname{Cov}(F)=I_{(m \times m)} \\
\operatorname{Cov}\left(\varepsilon_{i}, \varepsilon_{j}\right)=0, \operatorname{Cov}\left(F_{i}, \varepsilon_{j}\right)=0
\end{gathered}
$$

where $O$ is a matrix of zeros.

The above conditions ensure:

1) the independence of the factors,

2) the independence of the specific error terms, and,

3) the independence of the specific error terms and the latent factors.

The latent factors are responsible for the observed correlations amongst the indicator variables $X_{1}, X_{2}, \cdots, X_{P}$, as hinted above. For a factor solution with $F_{1}, F_{2}, \cdots, F_{m}$ uncorrelated, the simple correlations (structure loadings) between the factors $F_{j}, j=1,2, \cdots, m$ and the indicator variables $X_{i}, i=1,2, \cdots, p$ are the same as the coefficients (pattern loadings) $l_{i j}$.

The value of $l_{i j}^{2}$ is then the variance $F_{j}$ has in common with that $X_{i}$, so

$$
l_{i 1}^{2}+l_{i 2}^{2}+\cdots+l_{i m}^{2}
$$

is the total variance (communality) shared between $X_{i}$ and all $m$ factors [32] [33] [34] [35].

\subsubsection{Principal Component Factoring}

Principal Component Factoring (PCF) is one of several techniques used to perform factor analysis. In this approach, Principal Component Analysis [33] [35] is used to study the correlations between the indicator variables, which enables one to tease out the latent dimensions responsible for the correlations amongst the indicator variables. As many linear combinations (Principal Components (PCs)) of the indicator variables as the number of indicator variables, which are uncorrelated, are formed. The PCs are formed in such a way that the highest variance in the data is accounted for by the first PC, with successive PCs accounting for the highest of the remaining variance unaccounted for by the leading PCs, so that the last PC accounts for the least of the variability in the data. The higher the total variance accounted for by the first few PCs, the better the situation in trying to achieve data reduction, by replacing the original set of variables with the first few PCs as the new variables. This facilitates the interpretation of the correlations amongst the manifest variables while accounting for much of the information in the original data as possible [32] [33] [34] [35].

To ensure the principal components $C_{1}, C_{2}, \cdots, C_{p}$ specified below are uncorrelated with constrained variance, the coefficients (weights)

$$
\begin{aligned}
w_{i j}, i=1, \cdots, p ; j=1, \cdots, p & \text { are found } \\
C_{1} & =w_{11} X_{1}+w_{12} X_{2}+\cdots+w_{1 p} X_{p} \\
C_{2} & =w_{21} X_{1}+w_{22} X_{2}+\cdots+w_{2 p} X_{p} \\
\vdots & \\
C_{p} & =w_{p 1} X_{1}+w_{p 2} X_{2}+\cdots+w_{p p} X_{p}
\end{aligned}
$$


conditional on Equations (1) and (2) respectively [33] [34] [35].

$$
w_{i}^{\prime} \cdot w_{j}=0 \text { for all } i \neq j
$$

and

$$
w_{i}^{\prime} \cdot w_{i}=1
$$

where

$$
w_{i}^{\prime}=\left(w_{i 1}, w_{i 2}, \cdots, w_{i p}\right)
$$

The principal components can be formed by

$$
Z_{i}=\frac{X_{i}-\mu_{i}}{\sigma_{i i}}
$$

$i=1, \cdots, p$, where the mean and the standard deviation of the observed variable $X_{i}$ are $\mu_{i}$ and $\sigma_{i i}$ respectively [33].

The vector of standardized variables could be written in matrix notation as

$$
Z=\left(V^{1 / 2}\right)^{-1}(X-\mu)
$$

where

$$
\mu^{\prime}=\left(\mu_{1}, \mu_{2}, \cdots, \mu_{p}\right)
$$

and

$$
V^{1 / 2}=\left[\begin{array}{cccc}
\sigma_{11} & 0 & \cdots & 0 \\
0 & \sigma_{22} & \cdots & 0 \\
\vdots & \vdots & \ddots & \vdots \\
0 & 0 & \cdots & \sigma_{p p}
\end{array}\right]
$$

with

$$
\begin{gathered}
E\left[Z_{i}\right]=0, \\
\operatorname{Var}\left[Z_{i}\right]=1, i=1, \cdots, p
\end{gathered}
$$

and

$$
\rho=\operatorname{Cov}(Z)=\left(V^{1 / 2}\right)^{-1} \Sigma\left(V^{1 / 2}\right)^{-1}
$$

where

$$
\rho=\left[\begin{array}{cccc}
\frac{\sigma_{11}^{2}}{\sigma_{11} \sigma_{11}} & \frac{\sigma_{12}^{2}}{\sigma_{11} \sigma_{22}} & \cdots & \frac{\sigma_{1 p}^{2}}{\sigma_{11} \sigma_{p p}} \\
\frac{\sigma_{12}^{2}}{\sigma_{11} \sigma_{22}} & \frac{\sigma_{22}^{2}}{\sigma_{22} \sigma_{22}} & \cdots & \frac{\sigma_{2 p}^{2}}{\sigma_{22} \sigma_{p p}} \\
\vdots & \vdots & \ddots & \vdots \\
\frac{\sigma_{1 p}^{2}}{\sigma_{11} \sigma_{p p}} & \frac{\sigma_{2 p}^{2}}{\sigma_{22} \sigma_{p p}} & \cdots & \frac{\sigma_{p p}^{2}}{\sigma_{p p} \sigma_{p p}}
\end{array}\right]
$$

and 


$$
\Sigma=\left[\begin{array}{cccc}
\sigma_{11}^{2} & \sigma_{12}^{2} & \cdots & \sigma_{1 p}^{2} \\
\sigma_{21}^{2} & \sigma_{22} & \cdots & \sigma_{2 p}^{2} \\
\vdots & \vdots & \ddots & \vdots \\
\sigma_{p 1}^{2} & \sigma_{p 2}^{2} & \cdots & \sigma_{p p}^{2}
\end{array}\right]
$$

are the respective correlation and the variance-covariance matrces of $X$.

The covariance $\rho_{i j}$ between variables $X_{i}$ and $X_{j}$ is given by

$$
\rho_{i j}=\frac{\sum_{k=1}^{n}\left(x_{k i}-\mu_{i}\right)\left(x_{k j}-\mu_{j}\right)}{n}, i \neq j
$$

each of which is computed with $n$ observations.

If $\left(\lambda_{i}, e_{i}\right), i=1,2, \cdots, p$ are the eigenvalue-eigenvector pairs of $\rho$ such that $\lambda_{1} \geq \lambda_{2} \geq \cdots \geq \lambda_{p} \geq 0, e_{i}^{\prime} \cdot e_{j}=0$ and $e_{i}^{\prime} \cdot e_{j}=0$. Then

$$
C=A^{\prime} Z
$$

where $C^{\prime}=\left[C_{1}, C_{2}, \cdots, C_{p}\right]$ are the $p$ principal components and $A=\left[e_{1}, e_{2}, \cdots, e_{p}\right]$.

$$
\operatorname{Var}\left(C_{i}\right)=e_{i}^{\prime} \rho e_{i}=\lambda_{i}
$$

and

$$
\sum_{i=1}^{p} \operatorname{Var}\left(C_{i}\right)=\sum_{i=1}^{p} \operatorname{Var}\left(Z_{i}\right)=p
$$

The initial communality of each indicator variable in Principal Component Factoring is one. The entity $\lambda_{j} / p$ is the proportion of the variance in the data due $C_{j}$ and

$$
\operatorname{Corr}\left(C_{i}, Z_{j}\right)=e_{i j} \cdot \lambda_{j}^{1 / 2}
$$

is the loading of standardized variable $Z_{j}$ on any $C_{i}$ (correlations between a given PC $C_{i}$ and a given $Z_{j}$ ). Given the effect of the other variables $Z_{k}$, $j \neq k$, the loading of each $Z_{j}$ on each $C_{i}$ expresses the extent to which each $C_{i}$ is impacted by $Z_{j}$ [32] [33] [35].

While the application of principal component factoring is fairly common, its current application is uncommon in the extant literature on studies on factors influencing selection of banks in the Ghanaian context, particularly literature involving studies on selection of banks by Technical University students. Hence the relevance of this study.

\section{Results and Discussions}

The results of the data analysis is presented in this section. Owing to the nature of the results, each piece of result is immediately followed by a discussion of its implications in order to obviate the irritation that could results from having to recount the results if the presentation of the results was separated from the discussion thereof. Figure 1 shows a simplified flowchart of the method of the analysis.

\subsection{Suitability of Data for Factor Analysis}

Kaiser-Meyer-Olkin (KMO) measure of sampling adequacy and Bartlett's Test of 


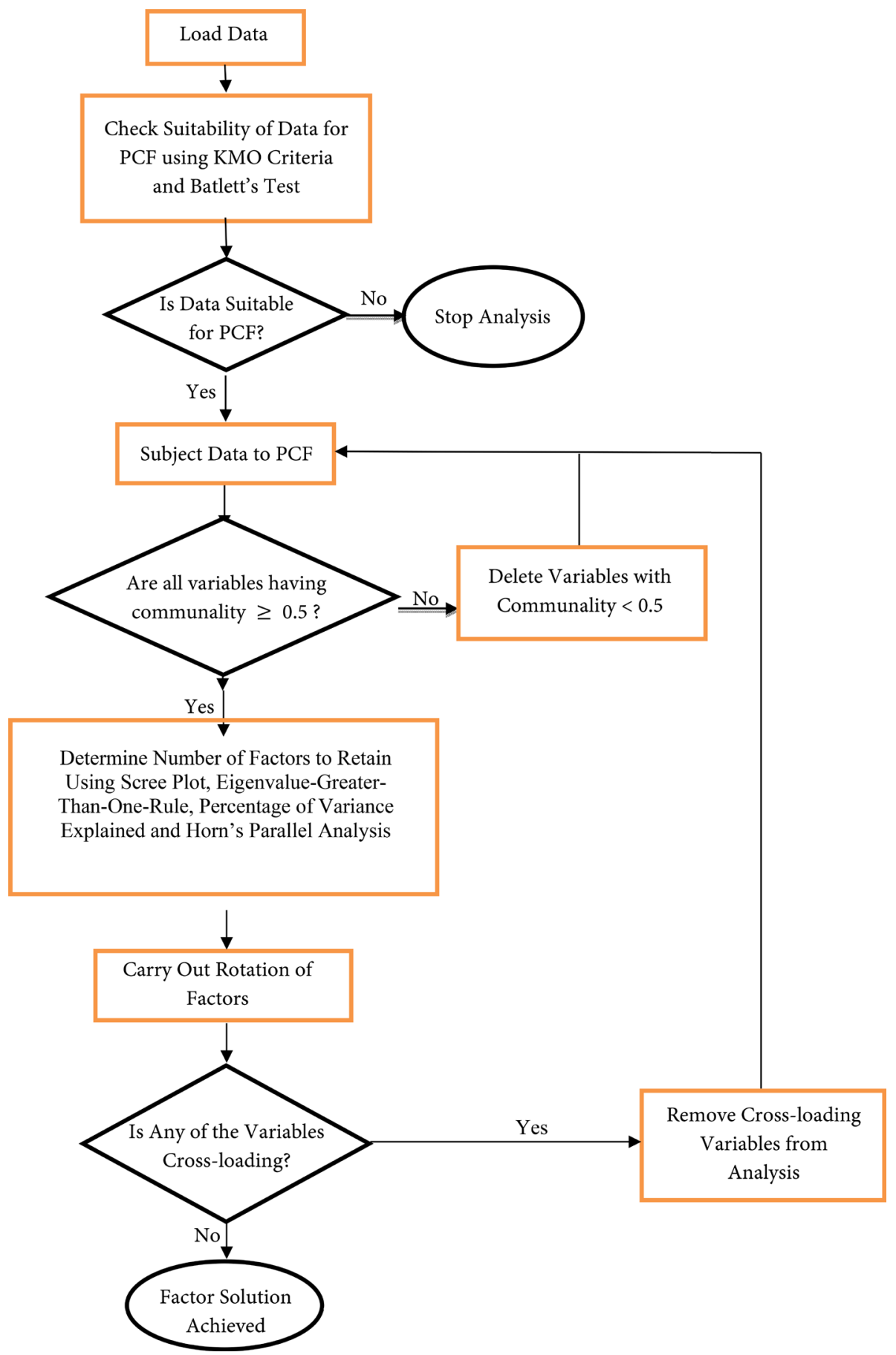

Figure 1. Simplified flowchart of the method of analysis.

Sphericity are two criteria that are used to determine the suitability of a given data for factor analysis [32]. The results for the KMO measure of sampling adequacy and the Bartlett's test for the suitability of the correlation matrix of the study data for factor analysis is as shown in Table 1. The overall KMO value of 0.86 (the least for the individual items is 0.67 ) is greater than the recommended threshold of 0.50 and the Bartlett's test $p$-value is $0.000(<0.05)$ [32] [35]. These two values, respectively indicate that the sample size of 545 is adequate and the 
correlations amongst some of the variables, if not all, are significant enough to warrant the use of factor analysis in trying to understand the dimensions the influence the choice of banks amongst the students.

As indicated in Section 2.2.3, the initial variance an indicator variable shares with all associated underlying factors is one (1) in PCF. Table 2 shows the initial and final total variance (communalities) each indicator variable shares with the common factors. The analysis was started with twenty-five (25) variables. However only thirteen (13) of them remained in the final factor solution, as the other twelve (12) of the variables were removed from the analysis for loading on more than one factor or having communality of less 0.50 in the preliminary analysis. As can be seen in Table 2, all the variables in the final factor solution have a final communality of 0.50 or more. Thus each variable in the final factor solution accounted for $50 \%$ or more of initial communality in the final factor solution. The final factor solutions is therefore considered reasonable.

\subsection{Number of Factors Extracted}

The percentage of variance explained by the retained factors (components), the eigen-value-greater-than-one rule, the scree plot and Horn's parallel analysis were used to decide on the number of factors to retain for interpretation [32] [35]. The first four components together account for $63.1 \%$ (see fourth row, Table 3 ) of the variability in the data. This value is more than the threshold of $60 \%$ suggested by Hair, Black, Babin, Anderson and Tatham [32]. Also the first four components have eigenvalues to be greater than one (see second column, Table 3). Thus by the eigenvalues-greater-than-one rule [32] [35], one can retain the

Table 1. Results for the KMO measure and Bartlett's test.

\begin{tabular}{cc}
\hline Kaiser-Meyer-Olkin measure of sampling adequacy & 0.860 \\
Bartlett's Test of Sphericity: Approximate. Chi-Square & 2025.243 \\
Degrees of freedom & 78 \\
Significance & 0.000 \\
\hline
\end{tabular}

Table 2. Initial and final communalities of variables.

\begin{tabular}{|c|c|c|c|c|c|}
\hline Variable & Initial & Extraction & Variable & Initial & Extraction \\
\hline Digital platforms & 1.00 & 0.65 & Pleasant bank atmosphere & 1.00 & 0.62 \\
\hline $\begin{array}{c}\text { Integration of mobile money } \\
\text { services }\end{array}$ & 1.00 & 0.55 & Influence of parents & 1.00 & 0.63 \\
\hline Convenience banking & 1.00 & 0.60 & The University uses the same bank & 1.00 & 0.67 \\
\hline Security & 1.00 & 0.54 & Financial benefits & 1.00 & 0.55 \\
\hline $\begin{array}{l}\text { Service provision (Range of } \\
\text { products on offer) }\end{array}$ & 1.00 & 0.59 & Availability of ATM on campus & 1.00 & 0.77 \\
\hline Staff courtesy & 1.00 & 0.69 & $\begin{array}{c}\text { Availability of } 24 \text { hours ATM } \\
\text { service }\end{array}$ & 1.00 & 0.71 \\
\hline Professionalism of bank staff & 1.00 & 0.64 & & & \\
\hline
\end{tabular}


Table 3. Total variance explained.

\begin{tabular}{cccc}
\hline \multirow{2}{*}{ Component } & \multicolumn{3}{c}{ Initial Eigen Values } \\
\cline { 2 - 4 } 1 & Total & \% of variance & Cumulative \% \\
\hline 2 & 4.460 & 34.307 & 34.307 \\
3 & 1.562 & 12.015 & 46.322 \\
4 & 1.158 & 8.906 & 55.228 \\
5 & 1.029 & 7.915 & 63.143 \\
6 & 0.740 & 5.691 & 68.834 \\
7 & 0.657 & 5.055 & 73.889 \\
8 & 0.612 & 4.708 & 78.598 \\
9 & 0.558 & 4.293 & 82.891 \\
10 & 0.527 & 4.058 & 86.948 \\
11 & 0.463 & 3.560 & 90.508 \\
12 & 0.438 & 3.372 & 93.880 \\
13 & 0.410 & 3.156 & 97.036 \\
\hline
\end{tabular}

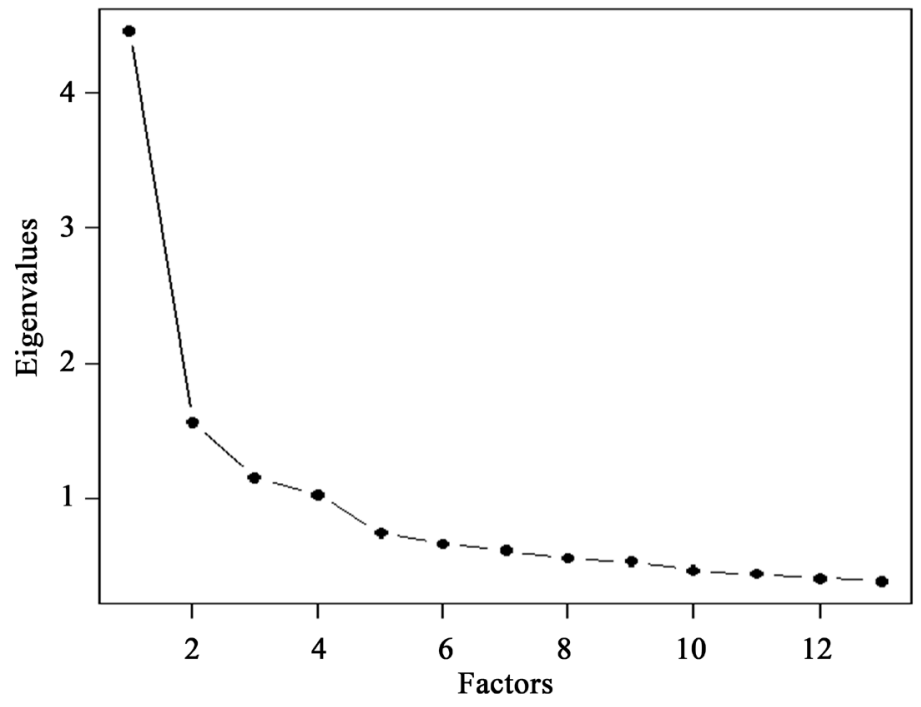

Figure 2. Plot of eigenvalues against factor number.

first four components for interpretation. Further, the scree plot of Figure 2 shows that the line plot begins to straighten out from the fifth component onwards, which also suggest retaining the first four components for interpretation. Additionally, Figure 3 and Table 4 shows the results of Horn's parallel analysis carried out on the data. As seen in Figure 3, the scree plot of the mean eigenvalues (EV) of simulated data (Random EV in blue) intersect the scree plot of the empirical data (unadjusted EV in red; adjusted EV in black) before the plot point of the fifth eigenvalue of the empirical data. Also, from Table 4, the adjusted eigenvalues of the first four factors are greater than zero (see Column 2 of Table 4), 


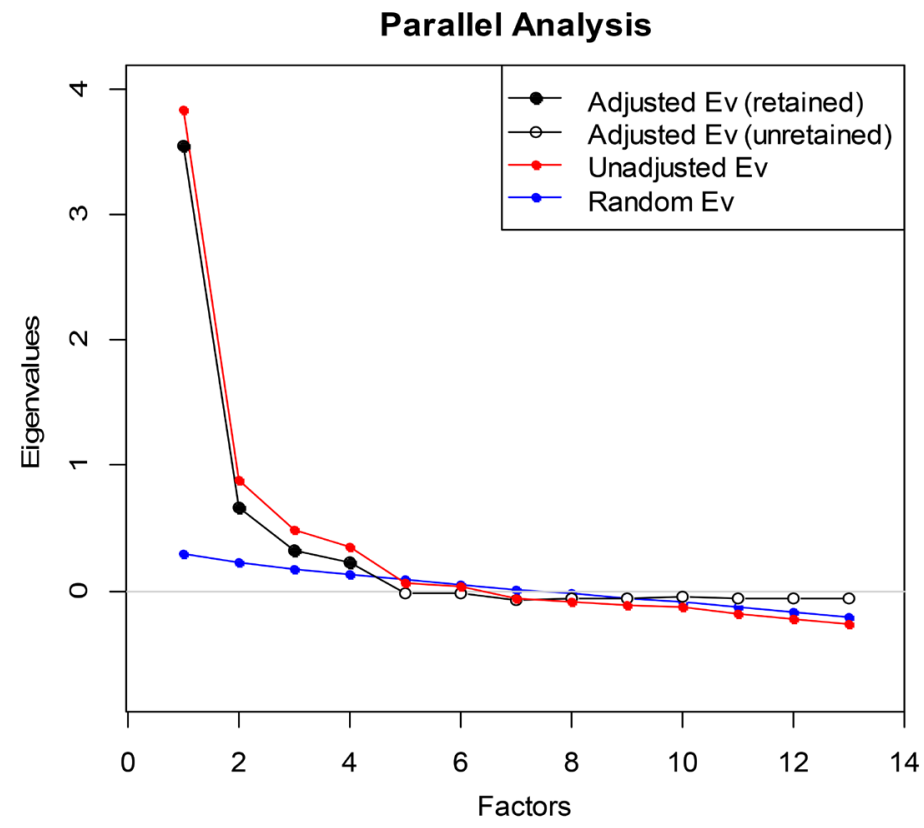

Figure 3. Plot of adjusted, unadjusted and random eigenvalues against factor number, depicting the factors to be retained for further interpretation.

Table 4. Results of Horn's Parallel Analysis for 5000 iterations using the mean estimate.

\begin{tabular}{cccc}
\hline Factor & Adjusted Eigenvalue & Unadjusted Eigenvalue & Estimated Bias \\
\hline 1 & 3.553 & 3.842 & 0.289 \\
2 & 0.658 & 0.880 & 0.222 \\
3 & 0.317 & 0.488 & 0.171 \\
4 & 0.225 & 0.352 & 0.126 \\
5 & -0.024 & 0.062 & 0.086 \\
6 & -0.018 & 0.031 & 0.049 \\
7 & -0.073 & -0.060 & 0.013 \\
8 & -0.060 & -0.082 & -0.022 \\
9 & -0.061 & -0.117 & -0.056 \\
10 & -0.042 & -0.132 & -0.091 \\
11 & -0.056 & -0.182 & -0.126 \\
12 & -0.056 & -0.220 & -0.164 \\
13 & -0.056 & -0.267 & -0.211 \\
\hline
\end{tabular}

Adjusted eigenvalues $>0$ indicate dimensions to retain; 4 factors retained.

indicating the first four components can be retained for interpretation [35] [36] [37]. A four factor solution appear to be adequate in explaining the underlying factor structure of the data given the results discussed above.

\subsection{Final Factor Solution}

Table 5 shows the final factor solution resulting from Varimax rotation of the 
Table 5. Rotated Component Matrix showing the loading of the variables on the factors.

\begin{tabular}{clcccc}
\hline & & \multicolumn{3}{c}{ Vomponents } \\
\cline { 3 - 5 } & & 1 & 2 & 3 & 4 \\
\hline$V_{1}$ & Digital platforms & 0.77 & & \\
$V_{2}$ & Integration of mobile money services & 0.72 & & \\
$V_{3}$ & Convenience banking & 0.70 & & \\
$V_{4}$ & Service provision (Range of products on offer) & 0.63 & & \\
$V_{5}$ & Security & 0.62 & & \\
$V_{6}$ & Staff courtesy & & 0.79 & \\
$V_{7}$ & Professionalism of bank staff & & 0.76 & \\
$V_{8}$ & Pleasant bank atmosphere & & 0.74 & \\
$V_{9}$ & Availability of 24 hours ATM service & & & 0.81 & \\
$V_{10}$ & Availability of ATM on campus & & & 0.79 & \\
$V_{11}$ & Influence of parents & & & & 0.78 \\
$V_{12}$ & The university uses the same bank & & & 0.74 \\
$V_{13}$ & Financial benefits & & & & \\
\hline
\end{tabular}

initial factor solution. The varimax rotation guarantees that the factors in the final factor solution are uncorrelated and each variable load highly on only one factor [32] [35]. The extent of correlation between a variable and a factor is expressed by the loadings, as indicated in Section 2.2.3. Thus the more influential a variable is on a factor, the higher the absolute value of its loading on the factor. For a sample size of 545 ( $>350$ ), a loadings of 0.30 is said to be significant [32]. To guarantee that the final factor solution is of real significance, a minimum loading threshold of 0.50 was used. The process of interpreting the final factor solution was expedited by suppressing loadings below the threshold and sorting those meeting the threshold to give prominence to influential variables, as shown in Table 5.

The naming of the factors (Components 1,2,3, and 4 (see Table 5)) was guided not only by the magnitude of the absolute value of the loadings of the manifest variables on the factors but also by their nature. The factors were named as follows: the variables loading on Factor 1 are $V_{1}$-digital platforms, $V_{2}$-integration of mobile money services, $V_{3}$-convenience banking, $V_{4}$-service provision and $V_{5}$-security. These variables together express use of digital technology to offer enhanced, secure and convenient banking services. Thus with the high loading of the variables bordering on digital technology, one is inclined to name Factor 1 as "robust e-banking". Factor 2 is influenced by $V_{6}$-staff curtesy, $V_{7}$-professionalism of bank staff and $V_{8}$-pleasant bank atmosphere. These variables have to do with what customers encounter when they deal with the bank. One is therefore persuaded to name Factor 2 "customer experience", taking cognizance of the high loading of the variables relating to the interaction between customers and bank staff. Factor 3 was named "access to ATMs" as the variables 
loading on it, $V_{9}$-availability of 24 hours ATM service and $V_{10}$-Availability of ATM on campus, are concerned with ease of access to ATMs. Amongst the three variables, $V_{11}$-influence of parents, $V_{12}$-the University uses the same bank and $V_{13}$-financial benefits, loading on Factor $4, V_{11}$ and $V_{12}$ which are more prominent in terms of their effect on Factor 4, border on the influence of entities who can be regarded as third parties to the relationship between a bank and its customers. Factor 4 was therefore named "third party influence". Thus the dimensions influencing choice of bank amongst TTU Students are:

Factor 1: Robust e-banking;

Factor 2: Customer experience;

Factor 3: Accessibility of ATMs;

Factor 4: Third party influence.

We learnt from the studies of Azumah, Rahman and Adzawla [9] and Abbam, Dadson and Sey [14] that customer service, efficiency of service, convenience banking, availability of technology, quality of service and short turnaround time are variables that influence bank choice. Application of technology in banking (otherwise captured as availability of technology) could engender service efficiency, make banking convenient, shorten turnaround time and thereby improve service quality. So the identification of robust e-banking (given its manifestations) as a factor that influence TTU students' bank choice is consistent with earlier research findings discussed above.

Two studies [18] [38] identified convenience of service, and service efficiency and meeting the needs of customers as influencing customer experience respectively. The current study has found staff curtesy, professionalism of bank staff and the ambience of the bank's premises as the determinants of customer experience.

Access to ATMs, as a factor that influence bank choice among students, is borne out by the results of some of the studies alluded to in the literature [10] [13] [14] [23]. Together, these studies pointed to availability, location and reliability of ATMs as impinging on the bank choice of prospective customers. So "access to ATMs" appear to be confirmed as a factor that influence bank choice among TTU students.

Indeed seven studies [13] [23] [25] [26] [27] [28] [29] cited in the introduction pointed to parties other than banks having influence on the bank choice of prospective customers, even though a study by Gerrard and Cunningham [30] arrived at the view that such influence is rather tenuous. Thus the results presented in this paper that "third party influence" is a factor that impacts TTU student's bank choice is in line with the findings of the above-mentioned seven studies and appears to be at variance with the view of Gerrard and Cunningham [30] on third party influence.

\section{Conclusions}

What the current study has shown is that some of the variables reckoned in the 
literature as having an influence on bank choice do not exist in isolation, but are manifestations of some latent dimensions which actually influence bank choice, in the case of the TTU students. As seen above, Factors 1 and 4 encapsulates a number of the variables mentioned in the literature in one form or the other, while the variables manifesting Factor 3 are somewhat direct reflections of what is in the literature as variables that influence bank choice. The variables that express Factor 2 are not the same as the variables that are said to constitute customer experience as recounted in the introduction.

The study also shows that banks, and for that matter corporate entities, wanting to understand what factors attract potential customers to them should not only take a cue from studies relating to the subject matter but should also conduct their own study to tease out the nuances in the factors or variables that impinge on customers choice of one bank (or corporate entity) over the other as there may be subtle differences in the attributes of the populace of the localities in which they operate compared to the localities in which some of the studies were conducted.

While there is the need to replicate the study reported in this paper in the other Technical Universities to ascertain what, in general, influence bank choice amongst Technical University students, banks can, to some degree, take a cue from the current study as to what to look out for when trying to understand and implement strategies to attract students, particularly Technical University students.

Two things could be done in furtherance of this work so that a broad-based conclusion could be arrived at, they include: firstly, surveying the remaining nine Technical Universities to have a comprehensive view of the factors technical university students consider in choosing their banks; and secondly, there is the need to determine if there are any gender differences in the factors that influence bank choice among students of Technical Universities.

\section{Conflicts of Interest}

The authors declare no conflicts of interest regarding the publication of this paper.

\section{References}

[1] Dabone, A.J., Brigit, A.O. and Biggles, P. (2013) Factors Affecting Customers Choice of Retail Banking in Ghana. International Journal of Research in Social Sciences, 3 , 16-25.

[2] Dogbe, C.S.K., Bamfo, B.A. and Sarsah, S.A. (2019) Determinants of Bank Selection by University Students in Ghana. International Journal of Developing and Emerging Economies, 7, 13-28.

[3] Amewu, G. and Mensah, S. (2014) Factors That Influence the Choice in Banks in Ghana. Review of Business Research, 14, 151-163.

[4] Mokhlis, S. (2009) Determinants of Choice Criteria in Malaysia's Retail Banking: An Analysis of Gender-Based Choice Decisions. European Journal of Economics, Finance and Administrative Sciences, No. 16, 18-28. 
[5] Gbadeyan, R.A. and Akinyosoye-Gbonda, O.O. (2011) Customers' Preference for e-Banking Services: A Case Study of Selected Banks in Sierra Leone. Australian Journal of Business and Management Research, 1, 108-116.

[6] Chigamba, C. and Fatoki, O. (2011) Factors Influencing the Choice of Commercial Banks by University Students in South Africa. International Journal of Biometrics, 6, 66-76. https://doi.org/10.5539/ijbm.v6n6p66

[7] Kumar, V., Batista, L. and Maull, R. (2011) The Impact of Operations Performance on Customer Loyalty. Service Science, 3, 158-171. https://doi.org/10.1287/serv.3.2.158

[8] Mokhlis, S., Mat, N.H.N. and Salleh, H.S. (2008) Commercial Bank Selection: Comparison between Single and Multiple Bank Users in Malaysia. International Journal of Economics and Finance, 1, 263-273. https://doi.org/10.5539/ijef.v1n2p263

[9] Azumah, S.B., Rahman, N.A. and Adzawla, W. (2014) The Determinants of Customers' Choice of Bank in the Tamale Metropolis of Ghana. ADRRI Journal (Multidisciplinary), 13, 16-31.

[10] Gakure, R.W. (2011) Factors That Influence the Retail Customer on the Choice of a Bank. Jomo Kenyatta University of Agriculture and Technology, Kenya.

[11] Duncan, G.J., Boisjoly, J. and Smeeding, T. (1996) Economic Mobility of Young Workers in the 1970s and 1980s. Demography, 33, 497-509. https://doi.org/10.2307/2061783

[12] Adekiya, A.A. and Gawuna, M.S. (2015) Bank Choice Determinant Factors: A Study of University Students in Metropolitan Kano. International Journal of Management Sciences, 6, 154-175.

[13] Blankson, C., Cheng, J.M.S. and Spears, N. (2007) Determinants of Banks Selection in USA, Taiwan and Ghana. International Journal of Bank Marketing, 25, 469-489. https://doi.org/10.1108/02652320710832621

[14] Abbam, A., Dadson, I. and Sey, J. (2015) An Empirical Analysis of Customer Bank Choice of Banks in Ghana. European Journal of Business Management, 7, 49-56.

[15] Khazeh, K. and Decker, W.H. (1992) How Customers Choose Banks. Journal of Retail Banking, 14, 41-45.

[16] Maiyaki, A.A. (2011) Factors Determining Bank's Selection and Preference in Nigerian Retail Banking. International Journal of Business and Management, 6, 253-257. https://doi.org/10.5539/ijbm.v6n1p253

[17] Akin, F. and Kaya, F. (2011) Factors Affecting Individual's Bank Choice. International Research Journal of Finance and Economics, 75, 100-107.

[18] Pass, M.W. (2006) Western US College Students: Banking Preferences and Marketplace Performance. Journal of Financial Services Marketing, 11, 49-63. https://doi.org/10.1057/palgrave.fsm.4760016

[19] Mariam, G.W. (2010) Bank Selection Decision: Factors Influencing the Choice of Banking Services. Master Thesis, Addis Ababa University, Addis Ababa.

[20] Rosenblatt, J. (1988) Commercial Banking in Canada: A Study of the Selection Criteria and Services Expectations of Treasury Officers. International Journal of Bank Marketing, 6, 19-30. https://doi.org/10.1108/eb010835

[21] Sudin, H. and Norafifah, A. (1992) Patronage Factors of Retail Customers towards Banks. Bankers Journal of Malaysia, 44-49.

[22] Owusu-Frimpong, N. (1999) Patronage Behaviour of Ghanaian Bank Customers. International Journal of Bank Marketing, 17, 335-342. 
https://doi.org/10.1108/02652329910305698

[23] Almossawi, M. (2001) Bank Selection Criteria Employed by College Students in Bahrain: An Empirical Analysis. International Journal of Bank Marketing, 19, 115-125. https://doi.org/10.1108/02652320110388540

[24] Karamustafa, K. and Yıldırım, M. (2007) A Research in the City of Kayseri, Relating to Consumers Bank Preferences. Journal of Economic and Social Research, 3, 56-92.

[25] Thomas Anderson Jr., W., Cox III, J.E.P. and Fulcher, D. (1976) Bank Selection Decisions and marketing Segmentation. Journal of Marketing, 40, 40-45.

https://doi.org/10.2307/1250674

[26] Kennington, C., Hill, J. and Rakowska, A. (1996) Consumer Selection Criteria for Banks in Poland. International Journal of Bank Marketing, 14, 12-21. https://doi.org/10.1108/02652329610119283

[27] Tan, C.T. and Chua, C. (1986) Intention, Attitude and Social Influence in Bank Selection: A Study in an Oriental Culture. International Journal of Bank Marketing, 4, 43-54. https://doi.org/10.1108/eb010783

[28] Yavas, U. (1988) Banking Behaviour in an Arabian Gulf Country: A Consumer Survey. International Journal of Bank Marketing, 6, 40-48. https://doi.org/10.1108/eb010842

[29] Denton, L. and Chan, A.K.K. (1991) Bank Selection Criteria of Multiple Bank Users in Hong Kong. International Journal of Bank Marketing, 9, 23-34. https://doi.org/10.1108/02652329110007129

[30] Gerrard, P. and Barton Cunningham, J. (1997) Islamic Banking: A Study in Singapore. International Journal of Bank Marketing, 15, 204-216. https://doi.org/10.1108/02652329710184433

[31] R Core Team (2020) R: A Language and Environment for Statistical Computing. R Foundation for Statistical Computing, Vienna. http://www.R-project.org/

[32] Hair, J.F., Black, W.C., Babin, B.J., Anderson, R.E. and Tatham, R. (2014) Multivariate Data Analysis. New International Edition, Pearson Education Ltd., London.

[33] Johnson, R.A. and Wichern, D.W. (2007) Applied Multivariate Statistical Analysis. 6th Edition, Prentice-Hall, Upper Saddle River.

[34] Everitt, B.S. and Dunn, G. (2001) Applied Multivariate Data Analysis. Arnold/Hodder Headline Group, London.

[35] Sharma, S. (1996) Applied Multivariate Techniques. John Wiley and Sons, Inc., USA.

[36] Schmitt, T (2016) Determining the Number of Factors with Parallel Analysis in R. https://www.r-bloggers.com/2016/04/determining-the-number-of-factors-with-para llel-analysis-in-r/

[37] Dinno, A (2014) Gently Clarifying the Application of Horn's Parallel Analysis to Principal Component Analysis versus Factor Analysis. https://alexisdinno.com/Software/files/PA_for_PCA_vs_FA.pdf

[38] Baah, E.M., Johnson, J.K.A. and Twenefour, F.B.K. (2015) A Statistical Model of Organizational Performance Using Factor Analysis-A Case of a Bank in Ghana. International Journal of Mathematics and Statistics Studies, 3, 38-46. 